\title{
ANALISIS WACANA KOHESI DAN KOHERENSI PADA WACANA IKLAN POLITIK DALAM WACANA PEMILU 2014
}

\author{
${ }^{1)}$ Yusep Ahmadi F., ${ }^{2}$ Reka Yuda Mahardika. \\ ${ }^{1)}$ yyusepp@yahoo.com \\ ${ }^{1.2)}$ Program Studi Pendidikan Bahasa dan Sastra Indonesia, STKIP Siliwangi
}

\begin{abstract}
ABSTRAK
Peneltian ini adalah penelitian analisis wacana dengan metode kualitatif-deskriptif.Objek penelitian ini adalah satu buah iklan politik partai Gerindra dan Partai Demokrasi Perjuangan (PDIP). Rumusan masalah penelitian ini adalah apa saja penanda kohesi dan koherensi yang terdapat pada iklan politik parati Gerindra dan PDIP. Hasil analisis menunujukkan penanda kohesi yang ditemukan dalam wacana iklan politik partai Gerindra adalah katafora dan repetisi sedangkan pada wacana iklan politik PDIP adalah anafora, substitusi dan konjungsi. Sementara itu, penanda koherensi yang ditemukan dalam iklan Partai Gerindra adalah hubungan perturutan, hubungan pararelisme, dan hubungan penjelasan atau identifikasi, sedangkan penanda koherensi yang ditemukan dalam wacana iklan PDIP adalah hubungan perturutan dan hubungan latar-simpulan. Temuan-temuan tersebut menunjukkan bahwa baik wacana iklan politik partai Gerindran maupun wacana iklan politik PDIP adalah wacana yang baik dan apik.
\end{abstract}

Kata Kunci: Kohesi, Koherensi, Iklan politik Partai Gerindra dan PDIP, Analisis Wacana

\begin{abstract}
This research is discourse analysis with qualitative methods-deskriptif.Objek this study is the fruit of political advertising Gerindra Party and Democratic Party of Struggle (PDIP). The research problems are any marker of cohesion and coherence found in political advertising parati Gerindra and PDIP. Results of analysis menunujukkan cohesion markers found in the discourse of political advertising Gerindra party is katafora and reps while the discourse of political advertising PDIP is anaphora, substitution and conjunction. Meanwhile, coherence markers found in advertising Gerindra is perturutan relationship, parallelism relationship, and the relationship explanation or identification, whereas the coherence markers found in advertising discourse PDIP is perturutan relationships and relationship-knot background. These findings indicate that neither party political advertising discourse and discourse Gerindran PDIP political advertising is a good discourse and slick
\end{abstract}

Keywords: Cohesion, Coherence, Political Ads Gerindra and PDIP, Discourse Analysis

\section{A. PENDAhuluan}

Wacana pemilu 2014 masih menyisakan banyak kesan dan pesan. Hal tersebut muncul akibat dari begitu beragam dan intensifnya iklan-iklan politik yang ditayangkan. Sebagai keniscayaan dalam berpolitik, sesungguhnya ada hubungan erat antara iklan politik dengan bahasa. Di antaranya, bahasa merupakan media efektif dalam iklan politik, berguna untuk menarik simpati, agar rakyat memilih calon yang diusung iklan politik tersebut pada waktu pencoblosan. Bahasa juga dapat menjadi 'amunisi' ampuh untuk membentuk citra, dan mengubah kondisi politik, bahkan sosial.

Iklan-iklan politik yang bermediakan bahasa merupakan bagian dari praktik sosial sebagaimana yang dikemukakanFairclough (1995b : 33-34) "Bahasa secara sosial dan historis adalah bentuk tindakan dalam hubungan dialektikal dengan struktur sosial". Oleh karena itu, konsekuensinya adalah iklan politik yang berasal dari organisasi politik tertentu niscaya hadir dengan membawa suara dan ideologi tertentu pula. Tujuannya, jelas, untuk melakukan tindak sosial dan perubahan sosial sesuai dengan visi dan misi dari ideologi yang diembannya. Agar visi dan misi atau ideologi itu tersampaikan dengan baik, sebuah wacana (iklan) perlu memiliki sarana kohesi dan koherensi, tanpa saran kohesi dan koherensi maka sebuah wacana tidak akan koheren dan kohesif dan itu mengakibatkan segala bentuk pesan di dalamnya tidak akan tersampaikan dengan baik. 
Berdasarkan asumsi di atas, peneliti merasa tertarik menganalisis sarana kohesi dan koherensi pada iklan-iklan politik pada masa pemilu 2014. Peneliti menentukan objek pada penelitian ini terbatas hanya pada satu iklan politik dari dua partai besar, yakni Partai Demokrasi Perjuangan (PDIP) dan Partai Gerakan Indonesia Raya (Gerindra). Dua partai itu sangat merepresentasikan iklan-iklan politik pada pemilu 2014 karena PDIP dan Partai Gerindra merupakan partai dengan jumlah kursi legislator terbanyak pertama dan peringgkat ketiga. Selain itu, dua partai itu sama-sama mengusung kadernya dan pimpinannya sebagai calon presiden tahun 2014.Pertimbangan itu merupakan landasan pemikiran mengapa iklan partai PDIP dan Gerindra saja yang diteliti.

Penelitian ini pada dasarnya merupakan penelitian lanjutan dari penelitian yang pernah dilakukan Ahmadi (2013) yang meneliti ideolgi iklan partai Gerindra pada pemilu 2014.Akan tetapi, penelitian sebelumnya tersebut belum secara tegas menganalisis kohesi dan koherensi wacana iklan partai Gerindra oleh karena itu penelitian ini diharapkan akan melengkapi dan mendapat temuan baru mengenai unsur-unsur kebahasaan dalam sebuah iklan politik.

Hasil penelitian ini juga diharapkan dapat memberikan pemahaman bagi mahasiswa agar mengetahui dan memahami perangkat linguistik dan luar linguistik yang mendukung keberadaan wacana tersebut. Selain itu mahasiswa diharapkan dapat pula memahami konsekuensi representasi, bahwa wacana iklan tersebut secara implisit memiliki ideologi tertentu. Sehingga pada akhirnya akan muncul kecerdasan dan kemampuan untuk mengkritisi, menyaring, dan mencari perspektif baru dari setiap informasi yang ada sebelum membuat kesimpulan. Penelitian ini juga direncanakan akan dikirim ke jurnal Semantik STKIP Siliwangi Bandung.

\section{B. KAJIAN TEORI DAN METODE}

\section{Kajian Teori}

\section{a. Kohesi dan Koherensi}

Kohesi adalah keserasian hubungan antara unsur yang satu dan unsur yang lain dalam wacana sehingga terciptalah pengertian yang apik atau koheren (Djajasudarma, 2006: 44). Koherensi adalah perihal mengenai cara klausa dihubungkan untuk membentuk kalimat, dan kalimat dihubungkan untuk membentuk teks atau wacana.
Kohesi merujuk pada perpautan bentuk, sedangkan koherensi pada perpautan makna (Djajasudarma, 2006: 44).Halliday (1976, dalam Mulyana, 2005:26) mengatakan bahwa kohesi wacana terbentuk dari ikatan sintaktikal. Kohesi tersebut dapat dikategrikan ke dalam dua jenis besar yakni kohesi leksikal, seperti sinonim, repetisi, kolokasi, dan kohesi gramatikal, seperti referensi, subtitusi, elipsis, dan konjungsi.

Sementara itu, menurut Kridalaksana (1984: 69 dalam Mulyana, 2005: 32) koherensi wacana sebenarnya adalah 'hubungan semantis'.Artinya hubungan itu terjadi antarproposisi.Secara struktural, hubungan itu direpresentasikan oleh pertautan secara semantis antara kalimat (bagian) yang satu dengan kalimat lainnya.Hubungan maknawi ini kadang-kadang ditandai oleh alat-alat leksikal, tetapi kadang-kadang juga tidak. Hubungan semantis itu antara lain adalah:

1) Hubungan sarana-hasil

2) Hubungan sebab-akibat

3) Hubungn alasan-sebab

4) Hubungan sarana tujuan

5) Hubungan latar-kesimpulan

6) Hubungan kelonggaran-hasil

7) Hubungan syarat-hasil

8) Hubungan perbandingan

9) Hubungan parafrastis

10) Hubungan aplikatif

11) Hubungan aditif waktu

12) Hubungan aditif non waktu

13) Hubungan identifikasi

14) Hubungan generik-spesifik

15) Hubungan ibarat

Beberapa pernyataan di atas dapat disimpulkan bahwa kohesi membentuk hubungan sintaktikal konkret-lahiriah, sedangkan koherensi merupakan pertautan makna atau proposisi yang cenderung bersifat abstrak-batiniah.

\section{b. Iklan Politik}

Iklan politik pasti terbangun dari dari sebuah konteks politik yang penu dengan tujuan ideologis. Iklan politik adalah salah satu dari bentuk komunikasi politik. Menurut Mark Roelofs dan Barn Lund (dalam Sumarno dkk. 2000: hlm.6)

"Politics is talk or to put the matter, more ecactly activity of politics (politicking) is talking"

Dari ungkapan kedua sarjana tersebut, walaupun dalam kalimat sangat sederhana namun cukup memberi isyarat bahwa komunikasi politik lebih 
memusatkan kajiannya pada bobot materi muatan yang berisi pesan-pesan politik atau dengan kata lain komunikasi politik adalah suatu proses dan kegiatan-kegiatan membentuk sikap dan perilaku politik yang terintegrasi ke dalam suatu sistem politik dengan menggunakan simbol-simbol yang berarti. Hal itu menunjukkan bahwa iklan politik dalah media komunikasi atau kekuatan komunikasi untuk mengatur masyarakat yang menjadi pembacanya.

Sementara itu, pendapat Nimmo (1999: hlm.135) seperti yang telah disinggung di muka mengatakan bahawa "dunia periklanan politik ialah periklanan citra, yaitu imbauan yang ditujukan untuk membina reputasi pejabat pemerintah atau yang menghendaki menjadi pejabat pemerintah; memberi informasi kepada khalayak tentang kualifikasi, pengalaman, latar belakang, dan kepribadian seorang politikus; dan meningkatkan prospek pemilihan kandidat atau mempromosikan program dan kebijakan tertentu.

\section{Metode}

Penelitian ini adalah penelitian kualitatif dengan menggunakan metode deskriptif. Penelitian kualitatif adalah penelitian yang menghasilkan prosedur analisis yang tidak menggunakan prosedur analisis statistik atau cara kuantifikasi lainnya. Penelitian kualitaif ini disesuaikan dengan teori analisis wacana model Fairclough (1989; 1992; 1995a;1995b).

Moleong (2005:6) menegaskan bahwa penelitian kulaitatif adalah penelitian yang bermaksud untuk memahami fenomena tentang apa yang dialami oleh subjek penelitian misalnya perilaku, persepsi, motivasi, tindakan, dll., secara holistik, dan dengan cara deskripsi dalam bentuk kata-kata dan bahasa, pada suatu konteks khusus yang alamiah dan dengan memanfaatkan berbagai metode alamiah. Artinya, penelitian ini tidak memberikan perlakuan terhadap data penelitian. Sementara itu, Secara perinci metode deskriptif adalah metode yang berusaha memberikan gambaran secara sistematis, faktual, dan akurat mengenai data, sifat-sifat serta hubungan fenomena-fenomena yang diteliti. (Djajasudarma: 1993 : 9).

Data berupa satu buah iklan Politik Partai Gerindra dan PDIP 2014, dikumpulkan apa adanya sebagaimana yang didapat. Kemudian data tersebut divalidasi melalui tahap trianggulasi data, yaitu dengan cara mencari pendapat atau orang lain terhadap data tersebut. Penelitian ini akan menggambarkan fenomena secara alamiah tanpa rekayasa.

\section{HASIL DAN PEMBAHASAN}

Pada dasarnya, penelitian ini beranjak dari pernyataan Mc Guigan yang dikembangkan kembali oleh Mahsun (2005) bahwa masalah penelitian itu dimungkinkan muncul atas tiga keadaan: (1) adanya informasi yang mengakibatkan munculnya kesenjangan dalam pengetahuan; (2) adanya hasil-hasil penelitian yang bertentangan; (3) adanya suatu kenyataan dan kita bermaksud menjelaskannya melalui penelitian (dikutip kembali oleh Rahardi, 2009: 29). Peneliti berkeyakinan bahwa alasan pertama dan ketigalah yang menjadi kendali dalam penelitian ini.Untuk dapat melakukan penelitian yang ilmiah, penelitian harus dilakukan melalui prosedur dan sistematika yang jelas .Hal itu di antaranya dilakukan melalui penentuan metodologi dan teknik penelitian.

\section{Iklan Politik Partai PDIP}

\section{a. Transkripsi iklan berjudul Prabowo Idola}

\section{Bait 1}

Mentari bersinar di timur bangkitkan gairahnya. (1)

Dia hadir di tengah kita bagaikan Garuda. (2)

Kembalikan Indonesia jadi macan Asia. (3)

Di bumi persada pun tak sabar menantinya. (4)

Dari papua ke aceh mengharapkan dia. (5)

Karisma kelembutannya. (6)

Berwibawa penuh perhatian. (7)

\section{Bait 2}

Prabowo pilihan kami. (8)

Prabowo idola kami. (9)

Prabowo pilihan kami. (10)

Prabowo pimpinan kami. (11)

Prabowo presiden kami. (12)

Iklan di atas merupakan iklan politik yang berbentuk sebuah syair lagu.Beberapa oang yang mewakili kalangan muda Indonesia menyanyiakn lagu tersebut. Untuk memudahkan analisis, data dibagi ke dalam dua bagian, yaitu bait pertama dan ada bait kedua.

\section{b. Kohesi dan Koherensi}

Wacana iklan di atas berbentuk sebuah syair lagu.Lagu tersebut memiliki banyak unsur kohesi.Pada kalimat pertama (baris ke-1) terdapat kata ganti -nya pada kata gairahnya. Kata ganti 
tersebut merupakan katafora yang mengacu pada kata Prabowo. Kata prabowo hadir sebagai anteseden kata ganti -nya tersebut di belakang.Selain kata ganti -nya yang melekat pada kata gairahnya, bentuk bentuk kata ganti -nya tersebut juga melekat pada kata menantinya, dan kelembutannya.

Dua kata tersebut juga mengacu pada kata Prabowo.Di samping penggunaan kata ganti -nya juga terdapat kata ganti dia dalam wacana di atas. Kata ganti dia merupakan alat kohesi yang menghubungkan kalimat kedua dengan kalimat $8,9,10,11$. Kata ganti dia juga adalah bentuk katafora yang mengacu pada kata Prabowo. Untuk memahami kalimat 3 tidak ada penada kohesi yang dapat menghubungkan proposisi kalimat tersebut dengan proposisi pada kalimat yang lain, tetapi dalam kalimat tersebut terdapat kata frasa macan asia. Frasa tersebut dapat dianalisis secara unsur eksternal wacana.

Dalam diskursus ekonomi tahun 1990-an Indonesia dikenal sebagai salah satu macan asia dalam bidang ekonomi setelah berhasil menjadi negara swasembada pangan pada awal era 1990-an. Katafora -nya tersebut juga dapat dikategorikan sekaligus menjadi unsur repetisi dalam wacana ini karena kata ganti -nya diulang sebanyak tiga kali. Kata ganti dia juga seklaigus dapat dikategorikan sebagai penanda repetisi dalam wacana ini karena diulang sebanyak tiga kali. Selain itu, penanda kohesi pada bait kedua ditemukan banyak bentuk repetisi, yaitu repetisi kata Prabowo dan kami.Bentuk repetisi kata Prabowo diulang sebanyak lima kali, begitu juga kata ganti kami diulang sebanyak lima kali.

Sementara itu, koherensi antarkalimat 1 dengan 2, 3, 4, 5 tersebut merupakan hubungan perturutan. Dalam hal ini proposisi-proposisi pada kalimat 1,2,3,4,5,6, dan 7 bersamaan menerangkan perihal tokoh Prabowo. Secara kohesif dalam kalimatkalimat tersebut terdapat frasa nomial yang paralel yang sama-sama menjelaskan tokoh prabowo. Frasa tersebut adalah, bagaikan garuda, macan asia, karisma kelembutannya, penuh perhatian . Di samping itu, terdapat juga frasa verbal bangkitkan gairahnya, tak sabar menantinya, dan mengharapkan dia. Frasa-frasa tersebut juga bersifat paralel yang sama-sama menjelaskan tokoh Prabowo.

Pada bait kedua, koherensi antar kalimat ditunjukkan oleh penanda kohesi repetisi Prabowo. Di sini kata prabowo diulangi dari kalimat 8 sampai 12. Semnetara itu secara umum koherensi yang terbangur antara bait 1 dan bait dua adalah hubungan makna penjelasan. Yang dijelaskan adalah apa yang terdapat dalam baik kedua sedangkan penjelasnya adalah semua proposisi/kalimat yang terdapatdalam bagian pertama. Selain itu, koherensi yang muncul pada bait kedua adalah adanya hubungan pararelisme.Perhatikan data berikut.

Prabowo pilihan kami. (8)

Prabowo idola kami. (9)

Prabowo pilihan kami. (10)

Prabowo pimpinan kami. (11)

Prabowo presiden kami. (12)

Baris kedelapa hingga baris keduabelas sama-sama memiliki bentuk yang pararel yakni berbentuk kalimat nominal.Hal ini menunjukkan bahwa wacana syair ini merupakan wacana yang koheren. Secara umum penanda kohesi yang ditemukan adalah sebagai berikut: kata ganti kataforis dan repetisi. Sementara itu, penanda koherensi yang ditemukan dalam wacana di atas adalah hubungan perturutan, hubungan penjelasan (identifikasi), dan hubungan pararelisme.

\section{Iklan Politik PDIP}

\section{a. Transkripsi ( Indonesia adalah Kita)}

1. Indonesia adalah kita

2. Jatuh bangunnya ada di tangan kita

3. Tuhan telah melengkapkan kita semua prasayarat untuk menjadi bangsa yang hebat

4. Memang masih banyak persoalan, tetapi bukankah itu medan perjuangan

5. Cita-cita yang kita pilih memang berat, namun menyerah bukan pilihan

6. Hanya ada satu jalan, bersatu, bersatu, dan bersatu

7. Coblos no 4 Indonesia hebat

Iklan di atas merupakan tuturan monolog yang disampaikan oleh Megawati dan Puan Maharani sebagai tokoh pimpinan PDIP.

\section{b. Kohesi dan Koherensi}

Kata ganti kita dalam bait Indonesia adalah kita merujuk pada bangsa yang hebat. PDIP dalam iklan ini hendak memosisikan bahwa dirinya adalah bagian dari rakyat.Konsekuensinya, disebutkan dalam baris, jatuh bangunnya ada di tangan kita, bermakna bahwa jatuh bangunnya Indonesia berada di tangan bangsanya sendiri. Kata kita dalam wacana iklan tersebut berkohesi anafora 
pada kataIndonesia, sekaligus bersubstitusi dengan bangsa hebat.

Tuhan telah melengkapkan kita semua prasyarat untuk menjadi bangsa yang hebat. Dalam bait itu terdapat kata kitayang secara kohesi merujuk pada bangsa Indonesia. Pada kalimat empat ditemukan penanda kohesi konjungsi pertentangan, yaitu tetapi. Konjungsi tersebut mempertentangkan dua proposisi yang terdapat pada kalimat empat, yakni proposisi masih banyak persoalan dengan bukankah itu medan perjuangan. Selain itu, konjungsi pertentangan juga ditemukan pada kalimat 5, yaitu konjungsi namun.Konjungsi tersebut mempertentangkan dua proposisi yang berlawanan pada kalimat 5, yakni proposisi citacita yang kita pilih memang berat, dengan proposisi menyerah bukan pilihan.

Proposisi cita-cita berat itu secara kohesi bisa diselesaikan bila bersatu. Kata bersatu direpetisi tiga kali bersatu, bersatu, bersatu.Artinya, menurut PDIP (iklan tersebut) dibutuhkan persatuan.Kata "persatuan" secara anafora merujuk pada klausa bila ingin Indonesia hebat.

Koherensi yang terbangun dari kalimat 1 sampai kalimat 6 adalah koherensi yang bersifat hubungan perturutan.Sementara itu, kalimat 1 hingga 6 memiliki koherensi hubungan latar-simpulan dengan kalimat 7.Kalimat tujuh sebagai kalimat terakhir merupakan simpulan atau solusi bagi segala permasalah dari latar yang ada di penjelasan kalimat-kalimat sebelumnya.

\begin{tabular}{|c|c|c|c|}
\hline & $\begin{array}{c}\text { Partai } \\
\text { Gerindra }\end{array}$ & PDIP & \\
\hline $\begin{array}{l}\text { Penanda } \\
\text { Kohesi }\end{array}$ & $\begin{array}{l}\text { - Katafora } \\
\text { - Repetisi }\end{array}$ & $\begin{array}{l}\text { - Anafora } \\
\text { - Substitusi } \\
\text { - Konjungsi }\end{array}$ & \\
\hline $\begin{array}{l}\text { Penanda } \\
\text { Koherensi }\end{array}$ & $\begin{array}{l}\text { - Hubungan } \\
\text { perturutan } \\
\text { - Hubungan } \\
\text { pararelism } \\
\text { e } \\
\text { - Hubungan } \\
\text { penjelasan } \\
\text { (identifika } \\
\text { si) }\end{array}$ & 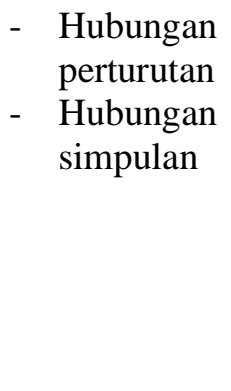 & latar- \\
\hline
\end{tabular}

\section{KESIMPULAN}

Hasil analisis menunjukkan bahwa iklan politik partai Gerindra dan PDIP sama-sama memiliki penada kohesi dan koherensi.Akan tetapi, penanda kohesi dan koherensi yang dimiliki kedua iklan politik tersebut memiliki perbedaan dan persamaan. Penanda kohesi yang ditemukan dalam wacana iklan politik partai Gerindra adalah katafora dan repetisi sedangkan pada wacana iklan politik PDIP adalah anafora, substitusi dan konjungsi. Sementara itu, penanda koherensi yang ditemukan dalam iklan Partai Gerindra adalah hubungan perturutan, hubungan pararelisme, dan hubungan penjelasan atau identifikasi, sedangkan penanda koherensi yang ditemukan dalam wacana iklan PDIP adalah hubungan perturutan dan hubungan latar-simpulan. Temuan-temuan tersebut menunjukkan bahwa baik wacana iklan politik partai Gerindran maupun wacana iklan politik PDIP adalah wacana yang baik dan apik.

\section{E. DAFTAR PUSTAKA}

Ahmadi, Yusep F. 2014. "Ideologi Iklan Partai Gerindra dalam Wacana Pemilu 2014: Analisis Wacana Kritis". Bandung. Prosiding Seminar Linguistik Tahunan 2014 Universitas Pendidikan Indonesia, halaman 744-749.

Ahmadi, Yusep F. 2014. "Ideologi Hizbut Tahrir Indonesia dalam Wacana Kenaikan Harga BBM 2013 di Buletin Al-Islam”. Bandung. Jurnal Metalingua Vol. 12.No. 2. Halaman 253-268.

Djajasudarma, T. Fatimah. 2006. Metode Linguistik: Ancangan Metode Penelitian dan Kajian. Bandung: PT Refika Aditama.

Eriyanto. 2001. Analisis Wacana Pengantar Analisis Teks Media.Yogyakarta : LkiS, 2001.

Firdaus, Winci. 2011. Sarana-sarana Kohesi Dalam Naskah Pidato Susilo Bambang Yudoyono: Analisis Wacana. Bandung. Jurnal Metalingua Vol. 9 Nomor 1.Halaman.99-109.

Mahsun. 2005. Metode Penelitian Bahasa. Jakarta: Rajagrafindo

Moleong, J. Lexy. 2005. Metode Penelitian Kualitatif. Bandung: Remaja Rosdak

Mulyana. 2005. Kajian Wacana: Teori, Metode, dan Aplikasi Prinsip-prinsip Wacana. Yogyakarta: Tiara Wacana.

Nimmo, Dan. 1999. Komunikasi Politik: Komunikator, Pesan, dan Media. Terj. Bandung. PT Rosdakarya 
Rahardi, Kunjana. 2009. Sosiopragmatik. Jakarta: Erlangga.

Sumarno, dkk. 2000. Dasar-dasar kominikasi politik. Bandung: Pasundan Law Faculty Alumnus Press. 